continuity of scientific work itself. For scientific workers, Mr. Butler poses clearly the question whether they are prepared to take up the arduous task with their fellow citizens of evolving means of arresting the drift to disaster, making their own special contributions to the solution of specified technical problems, or by their indifference and neglect allowing the forces of disruption and retrocession to gain strength until scientific workers are overwhelmed with the rest.

\title{
British and German University Enrolments
}

T another column (p. 175) we print an article on "Numerical Changes in the German Student Body" by Dr. E. Y. Hartshorne of Harvard, author of "German Universities and National Socialism". The main conclusions in Dr. Hartshorne's article may be summarized by saying that the reduction in number of students in German universities and seats of higher learning was approximately 42 per cent between 1932 and 1937, so that where there were a hundred in 1932 there were only fifty-eight in 1937. The process has since continued, and it seems probable that there are now not more than half the number of students in Germany that there were in 1932. Of the survivors, more than a third-approximately 34 per cent in 1937-were students of medicine. The great reductions have been in humanities, in 'pure' science and in law and allied studies. These conclusions naturally suggest an inquiry whether there are similar tendencies, if of a less degree, in the British student body. A preliminary investigation of the returns of the Universities Grants Committee shows that this question must be answered in the negative.

Since the academic year 1933-34, there has been a slight fall in the number of students entering British universities. The changes are of the order which those who administer universities regard as normally associated with fluctuations of prosperity. There is no reason to suppose that they have any permanent or deeply seated social causation. Moreover, within the British student body itself there are only minor fluctuations in the distribution of numbers. The British classifications are scarcely comparable to the German, but, with due reservations, it is possible to construct tentatively a comparative table of student groups in Great Britain and Germany, expressed as percentages of the total enrolment in each country. Such a table can be interpreted, however, only in the light of the enormous absolute fall in the total number of German students.

It will be seen that the highly significant drop, both relative and absolute, in the sciences and in engineering in the greatly diminished German student body has no parallel in the British universities. A distant analogy may be suggested in the rise in the percentage in 'medical studies' in the two countries. The relatively greater attention paid to these by British students is, however, easily explicable by the rise in importance of the social services in Britain and the increased demand for British trained medical men overseas.

\begin{tabular}{|c|c|c|c|c|c|}
\hline \multicolumn{6}{|c|}{ Percentages of Total ENROLMENT } \\
\hline & & & & $1932-33$ & $1936-37$ \\
\hline ‘Agriculture’, Great Britain & .. & .. & 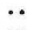 & $1 \cdot 6$ & 1.9 \\
\hline 'Agriculture, Germany & & & & & \\
\hline $\begin{array}{l}\text { 'Pure Science', Great Britain } \\
\text { 'Natural Science and Mather }\end{array}$ & näics', & German & & $\begin{array}{l}16 \cdot 7 \\
11 \cdot 1\end{array}$ & $\begin{array}{r}16 \cdot 3 \\
7 \cdot 0\end{array}$ \\
\hline 'Technology', Great Britain & .. & .. & . & $9 \cdot 0$ & 0 \\
\hline 'Ẽngineering', Germany & .. & .. & .. & $12 \cdot 5$ & $11 \cdot 4$ \\
\hline 'Medicine', Great Britain & 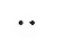 & . & $\cdots$ & $22 \cdot 4$ & $26 \cdot 7$ \\
\hline ‘Medical Sciences’, Germany & .. & .. &. & $27 \cdot 9$ & 33.9 \\
\hline
\end{tabular}

So far as foreign students are concerned, the movement in Great Britain is in the opposite direction to that in Germany. The report of the Universities Grants Committee notes that the number of students from overseas in British universities reached in 1936-37 the record figure of 6,792. This is an increase of about 50 per cent over 1932-33. Dr. Hartshorne records a decrease in the number of foreign students in Germany from 6,693 in 1932-33 to 4,768 in 1936-37. The "Universities Year Book of the British Empire" shows the countries of origin of students from abroad in British universities. The numbers from Germany in the six years 1932-33 to $1936-37$ were respectively $169,375,436,439,416,444$. These may be compared with the corresponding numbers of students from Holland: $46,55,42$, $55,69,58$; and from France : 80, 73, 81, 78, 76, 50 . We leave our readers themselves to judge whether the increase in the number of students from Germany since 1933 is due to an increased recognition of the advantages of study in Great Britain or to the racial and other limitations which are now imposed in that country upon entrance to universities. 